\title{
Multimodal measurements of brain tissue metabolism and perfusion in a neonatal model of hypoxic-ischaemic injury
}

Bale, Gemma, Rajaram, Ajay, Kewin, Matthew, Morrison, Laura, Bainbridge, Alan, et al.

Gemma Bale, Ajay Rajaram, Matthew Kewin, Laura Morrison, Alan Bainbridge, Linshan Liu, Udunna Anazodo, Mamadou Diop, Keith St. Lawrence, llias Tachtsidis, "Multimodal measurements of brain tissue metabolism and perfusion in a neonatal model of hypoxic-ischaemic injury," Proc. SPIE 11074, Diffuse Optical Spectroscopy and Imaging VII, 1107414 (11 July 2019); doi: 10.1117/12.2526729

SPIE. Event: European Conferences on Biomedical Optics, 2019, Munich, Germany 


\title{
Multimodal measurements of brain tissue metabolism and perfusion in a neonatal model of hypoxic-ischaemic injury
}

\author{
Gemma Bale $^{\mathrm{a}, *}$, Ajay Rajaram ${ }^{\mathrm{b}, \mathrm{c}}$, Matthew Kewin ${ }^{\mathrm{b}, \mathrm{c}}$, Laura Morrison ${ }^{\mathrm{b}}$, Alan Bainbridge ${ }^{\mathrm{d}}$, Linshan \\ Liu $^{\mathrm{b}}$, Udunna Anazodo ${ }^{\mathrm{b}, \mathrm{c}}$, Mamadou Diop ${ }^{\mathrm{b}, \mathrm{c}}$, Keith St. Lawrence ${ }^{\mathrm{b}, \mathrm{c}}$, Ilias Tachtsidis ${ }^{\mathrm{a}}$ \\ ${ }^{a}$ Medical Physics and Biomedical Engineering, University College London, Malet Place Engineering \\ Building, Malet Place, London, WC1E 6BT, UK; ' Imaging Program, Lawson Health Research \\ Institute, 268 Grosvenor St., London, ON, N6A 4V2, Canada; ' Department of Medical Biophysics, \\ Western University, 1151 Richmond St., London, ON, N6A 3K7, Canada; ${ }^{\mathrm{d} M e d i c a l}$ Physics and \\ Biomedical Engineering, University College Hospital, 25 Grafton Way, London, WC1E 6DB, UK \\ *g.bale@ucl.ac.uk; phone +44 207679 1571; www.ucl.ac.uk/medphys/research/borl/mms
}

\begin{abstract}
This is the first multimodal study of cerebral tissue metabolism and perfusion post-hypoxic-ischaemic (HI) brain injury with broadband near-infrared spectroscopy (bNIRS), diffuse correlation spectroscopy (DCS), positron emission tomography (PET) and magnetic resonance spectroscopy (MRS). In 5 piglet models of HI, we measured cerebral tissue saturation $\left(\mathrm{StO}_{2}\right)$, cerebral blood flow $(\mathrm{CBF})$, cerebral oxygen metabolism $\left(\mathrm{CMRO}_{2}\right)$, changes in the mitochondrial oxidation state of cytochrome-c-oxidase (oxCCO), cerebral glucose metabolism (CMRglc), and tissue biochemistry (Lac+Thr/tNAA). At baseline, the parameters measured were: $64 \pm 6 \% \mathrm{StO}_{2}, 35 \pm 11 \mathrm{ml} / 100 \mathrm{~g} / \mathrm{min} \mathrm{CBF}$, and $2.0 \pm 0.4$ $\mu \mathrm{mol} / 100 \mathrm{~g} / \mathrm{min} \mathrm{CMRO}_{2}$. After $\mathrm{HI}$ the parameters measured were: $68 \pm 6 \% \mathrm{StO}_{2}, 35 \pm 6 \mathrm{ml} / 100 \mathrm{~g} / \mathrm{min} \mathrm{CBF}, 1.3 \pm 0.1$ $\mu \mathrm{mol} / 100 \mathrm{~g} / \mathrm{min} \mathrm{CMRO}_{2}, 0.4 \pm 0.2 \mathrm{Lac}+\mathrm{Thr} / \mathrm{tNAA}$, and 9.5 $\pm 2.0 \mathrm{CMRglc}$. This study demonstrates the capacity of a multimodal set up to interrogate the pathophysiology of HIE using a combination of optical methods, MRS, and PET.
\end{abstract}

Keywords: broadband near-infrared spectroscopy, diffuse correlation spectroscopy, cytochrome-c-oxidase, multimodal

\section{INTRODUCTION}

Neonatal hypoxic-ischaemic encephalopathy (HIE) is a relatively common (1-3/1000 term births ${ }^{1}$ ) and potentially fatal (44-53\% of infants with HIE die or suffer disabilities ${ }^{1}$ ) healthcare problem. Magnetic resonance imaging and spectroscopy (MRI and MRS) are the imaging and prognostic modalities of choice, but they cannot provide continuous or cotside measurements of brain injury severity, perfusion, or metabolism. Optical devices such as near-infrared spectroscopy (NIRS) for cerebral haemodynamics or diffuse correlation spectroscopy (DCS) for cerebral blood flow $(\mathrm{CBF})$ give the opportunity for non-invasive, continuous, bedside monitoring, and have been demonstrated in neonatal intensive care units (NICU) to study $\mathrm{HIE}^{2,3}$. Using broadband NIRS (bNIRS), it is also possible to obtain a measurement of cellular metabolism via changes in oxidised cytochrome-c-oxidase (oxCCO, see review by Bale et al. ${ }^{4}$ ) and measure tissue saturation $\left(\mathrm{StO}_{2}\right)$ via broadband fitting ${ }^{5}$. The aim of this study is to demonstrate the capacity of a multimodal set up to interrogate the pathophysiology of HIE.

\section{METHODS}

\subsection{Animal Model}

Newborn piglets ( $<48$ hours old) were anesthetized, tracheotomized, and mechanically ventilated. Arterial oxygen saturation $\left(\mathrm{SaO}_{2}\right)$ was measured via a pulse oximeter attached to the piglet's right forelimb. DCS and bNIRS probes were secured to the left side of the head, avoiding the sagittal sinus, using an in-house 3D-printed probe holder. Hypoxicischaemic (HI) insult was induced by inflating occluders around the carotid arteries, followed by reducing the inspired oxygen from $21 \%$ to $8 \%$. HI was maintained for 10 to 20 minutes. At the end of the insult, recovery was initiated by deflating the carotid occluders and returning oxygen supply to baseline levels. Figure 1 shows the protocol schematic.

Diffuse Optical Spectroscopy and Imaging VII, edited by Hamid Dehghani, Heidrun Wabnitz, Proc. of SPIE-OSA Vol. 11074, 1107414 - @ 2019 SPIE-OSA · CCC code: 1605-7422/19/\$21 · doi: 10.1117/12.2526729 


\subsection{Multimodal Monitoring}

The optical system, a hybrid bNIRS and DCS device, has been fully described previously ${ }^{6}$. To avoid crosstalk between the systems, a shutter-based multiplexing approach was used. To obtain an absolute measurement of CBF in $\mathrm{ml} / 100 \mathrm{~g} / \mathrm{min}$, a dynamic contrast-enhanced (DCE) bNIRS procedure using an indocyanine green (ICG) tracer was performed at the end of the optical measurements. After the optical measurement, the piglets were transferred to a PETMRI scanner. FDG PET and ${ }^{1} \mathrm{H}$ MRS were performed to obtain cerebral metabolic rate of glucose (CMRglc) and the ratio to lactate and threonine to total NAA (Lac+Thr/tNAA) which is a surrogate marker of injury severity.

DCS and bNIRS measurements were analysed using MATLAB to yield oxy- and deoxy-haemolgobin $\left(\mathrm{HbO}_{2}\right.$ and $\left.\mathrm{HHb}\right)$ changes, oxCCO changes, cerebral oxygen saturation $\left(\mathrm{StO}_{2}\right), \mathrm{CBF}$, and cerebral metabolic rate of oxygen $\left(\mathrm{CMRO}_{2}\right)($ for details, see Rajaram et al.6). Recovery fractions of the optical signals were calculated as the ratio of the difference between the recovered signal and nadir of $\mathrm{HI}$ with the baseline signal and nadir of HI (equation in Table 1 caption).

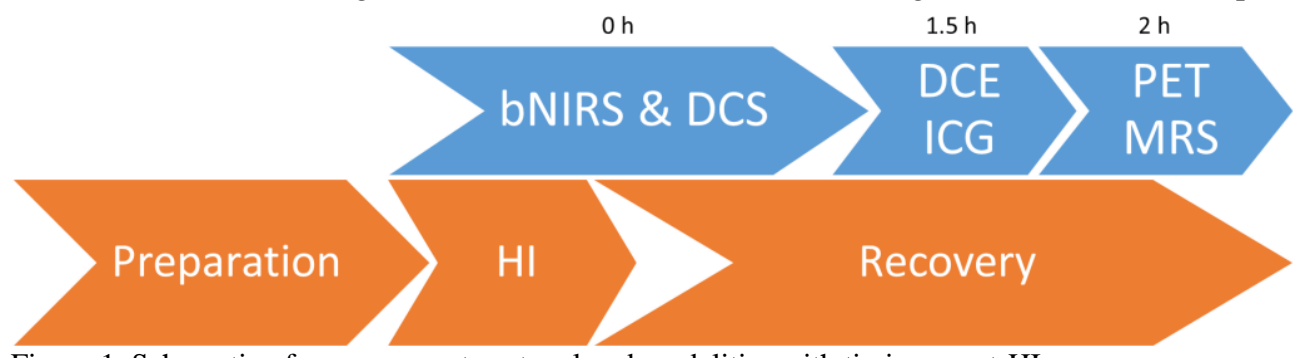

Figure 1. Schematic of measurement protocol and modalities with timings post-HI.

\section{RESULTS}

a)

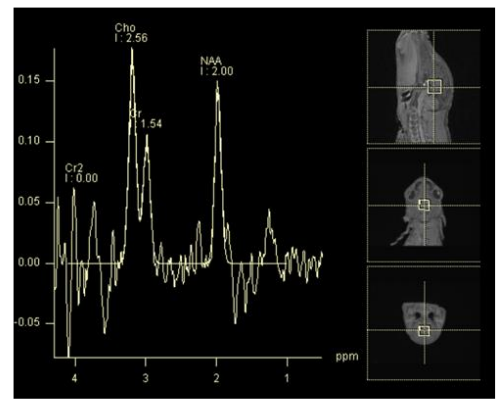

d)

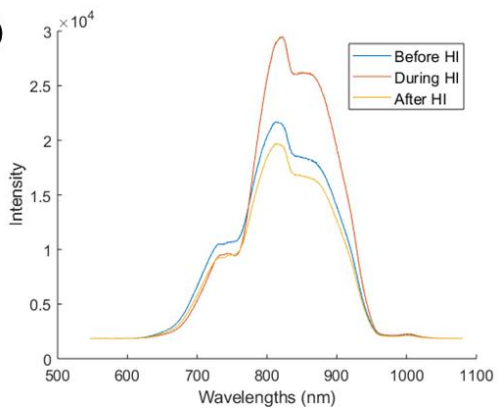

b)

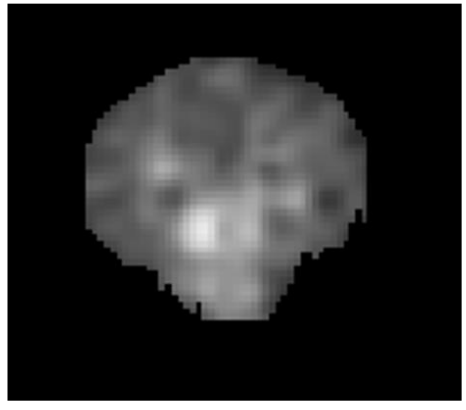

e).

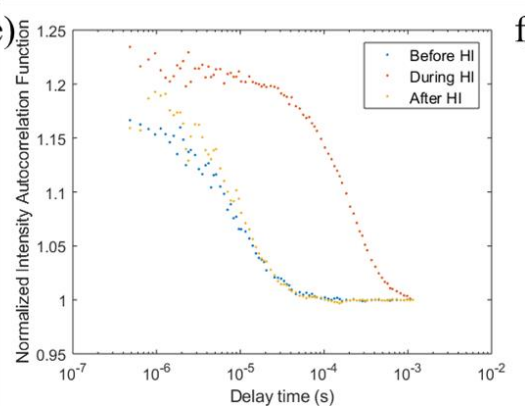

c)

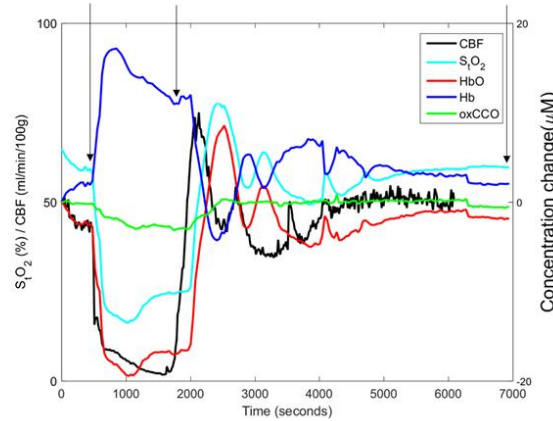

f)

\begin{tabular}{|l|l|l|}
\hline $\mathbf{C M R O}_{2}$ & \multicolumn{1}{|l|}{ CMRglc } & $\begin{array}{l}\text { Lac+Thr } \\
\text { /tNAA }\end{array}$ \\
\hline 1.2 & 13.2 & \\
$\mu \mathrm{mol} / 100 \mathrm{~g} / \mathrm{min}$ & $\mu \mathrm{mol} / 100 \mathrm{~g} / \mathrm{min}$ & 0.35 \\
\hline
\end{tabular}

Figure 2. Examples of data collected from all modalities in one piglet (piglet 26): a) basal ${ }^{1} \mathrm{H}$ MRS spectra and voxel location, b) FDG PET glucose map, c) bNIRS and DCS signals during HI; arrows indicate start and end of HI, and final measurement for RF, d) NIRS intensity spectra before, during and after HI, e) DCS normalized intensity autocorrelation functions before, during and after HI, f) results obtained from all modalities after $\mathrm{HI}$. 
Measurements on 5 piglets post-HI ( 2 females, age $23 \pm 10 \mathrm{~h}$, weight $1.6 \pm 0.2 \mathrm{~kg}$ ) of $\mathrm{HbO}_{2}, \mathrm{HHb}$, oxCCO, $\mathrm{StO}_{2}, \mathrm{CBF}$, $\mathrm{CMRO}_{2}, \mathrm{Lac}+\mathrm{Thr} / \mathrm{tNAA}$ and CMRglc were collected (see Table 1 for details). At baseline the parameters measured were: $64 \pm 6 \% \mathrm{StO}_{2}, 35 \pm 11 \mathrm{ml} / 100 \mathrm{~g} / \mathrm{min} \mathrm{CBF}$, and $2.0 \pm 0.4 \mu \mathrm{mol} / 100 \mathrm{~g} / \mathrm{min} \mathrm{CMRO}_{2}$. After $\mathrm{HI}$ the parameters measured were: $68 \pm 6 \% \mathrm{StO}_{2}, 35 \pm 6 \mathrm{ml} / 100 \mathrm{~g} / \mathrm{min} \mathrm{CBF}, 1.3 \pm 0.1 \mu \mathrm{mol} / 100 \mathrm{~g} / \mathrm{min} \mathrm{CMRO}_{2}, 0.4 \pm 0.2 \mathrm{Lac}+\mathrm{Thr} / \mathrm{tNAA}$, and $9.5 \pm 2.0$ CMRglc. Figure 2 shows examples of the multimodal data collected and the optical data recorded continuously for one piglet.

Table 1. Details of piglets studied with all variables measured after HI. Age is postnatal age at experiment start. CBF measured in $\mathrm{ml} / 100 \mathrm{~g} /$ minute, $\mathrm{CMRO}_{2}$ and $\mathrm{CMRglc}$ measured in $\mu \mathrm{mol} / 100 \mathrm{~g} / \mathrm{min}$. Recovery fractions of optical signals in $\%: \mathrm{RF}=$ recovery nadir/baseline-nadir x $100 \%$. *Note that the Lac+Thr/tNAA for piglet 31 was measured in the left cortex.

\begin{tabular}{|c|c|c|c|c|c|c|c|c|c|c|c|c|c|c|}
\hline Pig & $\begin{array}{l}\text { Age } \\
\text { (h) }\end{array}$ & $\begin{array}{l}\text { Weight } \\
\text { (kg) }\end{array}$ & Sex & $\begin{array}{l}\text { HI } \\
(\operatorname{mins})\end{array}$ & $\begin{array}{l}\mathrm{StO}_{2} \\
(\%)\end{array}$ & CBF & $\mathrm{CMRO}_{2}$ & CMRglc & Lac & $\begin{array}{l}\mathrm{HbO}_{2} \\
(\%)\end{array}$ & $\begin{array}{l}\text { HHb } \\
(\%)\end{array}$ & $\begin{array}{l}\text { oxCCO } \\
(\%)\end{array}$ & $\begin{array}{l}\mathrm{StO}_{2} \\
(\%)\end{array}$ & $\begin{array}{l}\text { CBF } \\
(\%)\end{array}$ \\
\hline 22 & 23 & 1.2 & $\mathrm{~F}$ & 10 & 70.4 & 35.7 & 1.2 & 8.6 & 0.11 & 103 & 98 & 105 & 100 & 101 \\
\hline 23 & 10 & 1.6 & $\mathrm{M}$ & 20 & 71.7 & 39.2 & 1.4 & 7.0 & 0.57 & 109 & 94 & 108 & 106 & 86 \\
\hline 26 & 24 & 1.5 & $\mathrm{M}$ & 20 & 64.1 & 42.0 & 1.2 & 13.2 & 0.35 & 105 & 91 & 110 & 114 & 94 \\
\hline 30 & 20 & 1.8 & $\mathrm{M}$ & 20 & 75.4 & 30.8 & 1.4 & 9.6 & 0.39 & 116 & 90 & 136 & 121 & 198 \\
\hline 31 & 40 & 1.7 & $\mathrm{~F}$ & 20 & 59.0 & 26.6 & 1.3 & 9.1 & $* 0.45$ & 140 & 77 & 168 & 114 & 73 \\
\hline
\end{tabular}

\section{DISCUSSION}

This is the first multimodal study of cerebral tissue metabolism and perfusion post-HI with optics, PET and MRS. This multimodal configuration allows us to investigate pathophysiology during HIE. It should be noted these measurements were not simultaneous, with optical measurements recorded before the PET and MRS measurements. Further, the low number of animals and small range of injury severity (determined by lactate ratio) means it is not possible at this stage to identify biomarkers or relationships between measurements. Tissue saturation is the most commonly used optical cerebral monitor in the NICU; the addition of bNIRS and DCS to the optical instrumentation gives insight into the cerebral metabolism $\left(\mathrm{CMRO}_{2}\right.$ and oxCCO) and perfusion continuously during treatment.

\section{ACKNOWLEDGEMENTS}

This project was funded by the Wellcome Trust (104580/Z/14/Z), Medical Research Council (MR/S003134/1), and Canadian Institutes of Health Research (CGP-140171).

\section{REFERENCES}

[1] Mitra, S., et al. "Proton magnetic resonance spectroscopy lactate/N-acetylaspartate within 2 weeks of birth accurately predicts 2-year motor, cognitive and language outcomes in neonatal encephalopathy after therapeutic hypothermia," Arch Dis Child Fetal Neonatal Ed 0, 1-9 (2018).

[2] Bale, G., et al. "Oxygen dependency of mitochondrial metabolism indicates outcome of newborn brain injury," J. Cereb. Blood Flow Metab. https://doi.org/10.1177/0271678X18777928 (2018).

[3] Dehaes, M., et al. "Cerebral oxygen metabolism in neonatal hypoxic ischemic encephalopathy during and after therapeutic hypothermia.," J. Cereb. Blood Flow Metab. 34(1), 87-94 (2014).

[4] Bale, G., Elwell, C. E. and Tachtsidis, I., "From Jöbsis to the present day: a review of clinical near-infrared spectroscopy measurements of cerebral cytochrome-c-oxidase," J. Biomed. Opt. 21(9), 091307 (2016).

[5] Yeganeh, H. Z., et al. "Broadband continuous-wave technique to measure baseline values and changes in the tissue chromophore concentrations.," Biomed. Opt. Express 3(11), 2761-2770 (2012).

[6] Rajaram, A., et al. "Simultaneous monitoring of cerebral perfusion and cytochrome c oxidase by combining broadband near-infrared spectroscopy and diffuse correlation spectroscopy,” Biomed. Opt. Express 9(6), 2588 (2018). 